\title{
Postoperative Hypertension
}

National Cancer Institute

\section{Source}

National Cancer Institute. Postoperative Hypertension. NCI Thesaurus. Code C9271.

A transient increase in blood pressure following a surgical procedure. 